\title{
Kinetic Modeling of Adsorption of Pb (II) Using Activated Carbon Prepared from Lapsi Seed Stone by Chemical Carbonization
}

\author{
Rajeshwar Man Shrestha* \\ Department of Applied Sciences, Institute of Engineering, Tribhuvan University, Nepal \\ Email: rajeshwar@ioe.edu.np
}

Activated carbon prepared from Lapsi Seed Stone by Chemical carbonization with concentrated suplhuric acid concentrated nitric acid has been applied to study the adsorption of Pb (II) ions. The optimal pH and contact time for the adsorption were found to be 5 and 3 hours respectively. Adsorption equilibrium data have been analyzed by Langmuir and Freundlich adsorption isotherms. It is found that equilibrium data is in good agreement with Langmuir adsorption isotherm as compared to Freundlich adsorption isotherm showing a maximum uptake of $277.28 \mathrm{mg} / \mathrm{g}$. The kinetic of the adsorption of the metal ions is evaluated by the pseudo first order and pseudo second order. The results indicate that pseudo second order provides a more appropriate description of the metal ion adsorption on the activated carbon. It has been concluded that the activated carbon prepared from Lapsi seed stone can be used as an effective adsorbent for the removal of $\mathrm{Pb}$ (II) from aqueous solution.

Keywords: Adsorption kinetics, Adsorption isotherms, Lead, Lapsi seed stone, Adsorption isotherm

\section{Introduction}

Lead, one of the highly toxic heavy metals released into water bodies by anthropogenic activities such as manufacturing process of stainless steels, super alloys, metallic alloys, coins, batteries etc .Direct exposure to nickel causes dermatitis. Some nickel compounds as carbonyl are carcinogenic and easily absorbed skin ${ }^{1}$. Acute poisoning of $\mathrm{Ni}$ (II) causes headache, dizziness, nausea and vomiting, chest pain, tightness of the chest, dry cough and shortness of breath, rapid respiration, cyanosis and extreme weakness ${ }^{2}$.The metal ions therefore should be reduced to lower level to the permissible before being discharged to water bodies The methods used to remove the heavy metal ions include chemical precipitation, chemical oxidation or reduction, filtration, ion exchange, electrochemical treatment, membrane filtration, reverse osmosis and adsorption.

However, most of these methods have drawbacks such as incomplete removal of heavy metals, high operational cost and problem for disposal of metallic sludge.

Adsorption process, therefore, has been mostly applied for the removal of pollutants from water. Many researches have been carried out work to find the cheaper ad chemico -physically feasible adsorbent $^{3}$

Many studies have shown the development of low cost activated carbon prepared from locally available and cheaper materials like apricot stone ${ }^{4}$, olive stone ${ }^{5}$, date stone ${ }^{6}$ peanut shell ${ }^{7}$ coconut shell $^{8}$, palm shell ${ }^{9}$, rice husk ${ }^{10}$ etc. for the production of activated carbon.

\footnotetext{
* Corresponding author
} 
In present study, kinetics of $\mathrm{Pb}$ (II) adsorption onto PAALSSC (Phosphoric acid activated Lapsi Seed Stone carbon) has been studied through a pseudo-first-order ${ }^{11,12}$ a pseudo-second-order ${ }^{13,14}$.Adsorption isotherm usually gives an information about the equilibrium state between the amount of adsorbed metal ion onto the adsorbent surface and the concentration of metal ions in solution. Langmuir ${ }^{15,16}$ and Freundlich ${ }^{17}$ are the most commonly applied adsorption isotherms.

\section{Materials and Methods}

\section{Materials}

The materials used for the preparation of activated carbon were Lapsi seed stones which were collected from Paun Bhandar, Godawari, Lalitpur, Nepal. The seed stones were first washed with tap water and then with distilled water to remove impurities, dried at $110^{\circ} \mathrm{C}$ for 24 hours. They were crushed with mortar and electric grinder into fine particles. The crushed particles were then sieved to obtain the fraction of $300 \mu \mathrm{m}$.

\section{Preparation of Activated carbon}

The activated carbon was prepared by chemical carbonization with treatment of concentrated sulphuric acid. The grinded particles of Lapsi seed stone were treated with concentrated $\mathrm{H}_{2} \mathrm{SO}_{4}$ in 1:1 weight ratio and kept in an oven maintained at a temperature of $150^{\circ} \mathrm{C}$ for 24 hours [9]. The particles were then washed with distilled water till the $\mathrm{pH}$ and conductivity of the washing were equal to that of distilled water. The particles were dried in an oven at $110^{\circ} \mathrm{C}$ for 10 hours. The particles were then ground and sieved to get the particles size of $106 \mu \mathrm{m}$. The activated carbon prepared has been used to study the adsorption kinetics and adsorption isotherms.

\section{Adsorption studies}

Batch adsorption experiments were carried out in a series of stoppered reagent bottles. A weighed amount $(0.05 \mathrm{~g})$ of adsorbent was introduced into the reagent bottles $(50 \mathrm{ml})$ containing various concentration of the heavy metal. The total volume of the aqueous solution is equal to $25 \mathrm{ml}$. The solution of $0.1 \mathrm{M} \mathrm{HCl}$ and $0.1 \mathrm{M} \mathrm{NaOH}$ have been used to adjust the $\mathrm{pH}$ of the solution. The bottles were then shaken at room temperature $\left(25 \pm 2{ }^{\circ} \mathrm{C}\right)$ using an electric shaker for a prescribed time to attain the equilibrium. The concentrations of metal ions were determined by using an atomic absorption spectrophotometer. The instrument calibration was checked by using standard metal solutions.

The amount of heavy metal adsorbed was calculated by the following mass balance equation.

$$
\mathrm{q}_{\mathrm{e}}=\frac{\left(\mathrm{C}_{\mathrm{o}}-\mathrm{C}_{\mathrm{e}}\right) \times \mathrm{V}}{\mathrm{W}}
$$

Where $\mathrm{Co}$ and Ce are initial and equilibrium concentration of metal ion $(\mathrm{mg} / \mathrm{L})$ respectively, $\mathrm{m}$ is the mass of adsorbent in gram $(\mathrm{g})$ and $\mathrm{V}$ was the volume of the solution in liter $(\mathrm{L})$.

\section{Results and Discussion}

\section{Effect of contact time}

The percentage removal of the metal ions increases with increase in time and attains a maximum value at about 180 minutes as show in Figure 1. The adsorption rate is very fast initially up to 100 minutes and 


\section{J. Nepal Chem. Soc., Vol. 36, 2017}

then after it attains equilibrium value slowly. The fast adsorption at initial stage may be due to the higher driving force due to the availability of the large concentration of active sites for adsorption. After 100 minutes the percentage of removal increases gradually and attains plateau value at 180 minutes. At equilibrium all the active sites will be covered by the metal ions and no further adsorption of metal ions occurs. Hence the optimum contact time for the removal of the heavy metal by the adsorbent is found to be 180 minutes.

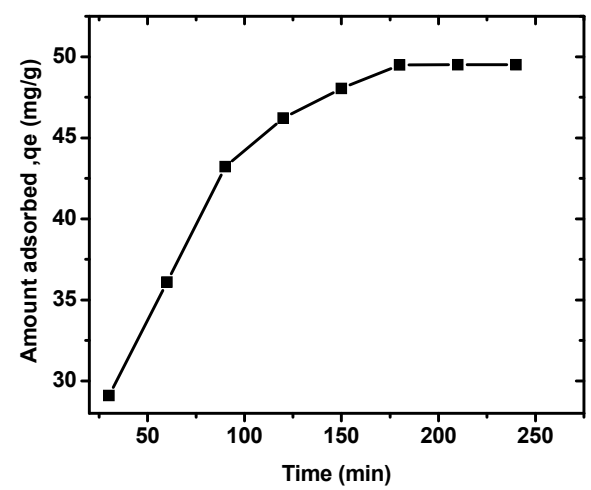

Figure 1: Effect of contact on adsorption of $\mathrm{Pb}$ (II)

\section{Effect of pH}

The effect of $\mathrm{pH}$ on adsorption of $\mathrm{Pb}$ (II) on the activated carbon was studied over the $\mathrm{pH}$ range of 27. The percentage removal of metal ions against $\mathrm{pH}$ is shown in Fig. 2. The percentage removal of metal ions increases with increase in $\mathrm{pH}$.

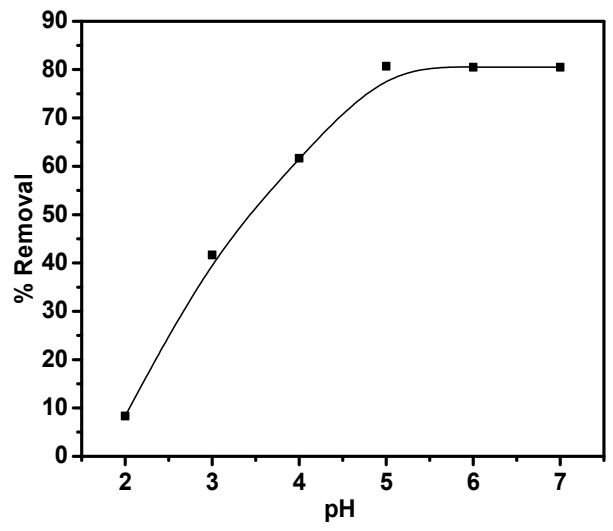

Figure 2: Effect of $p H$ on adsorption of $\mathrm{Pb}$ (II)

The percentage removal of $\mathrm{Pb}$ (II) reached a maximum at $\mathrm{pH}$ 5, and then after it remains almost constant; similar results were also observed by Barka ${ }^{18}$. The percentage of removal of $\mathrm{Pb}$ (II) is low at low $\mathrm{pH}$. This lower percentage of removal of metal ions may be due to the fact that at lower $\mathrm{pH}$ there is higher concentration of hydrogen ions and that competes with metal ions. Owing to this the percentage removal

$-116-$ 
of metal ions from aqueous solution is low. Moreover at higher $\mathrm{pH}$, the acidic surface functional groups (eg $-\mathrm{COOH},-\mathrm{OH}$ etc.) present on carbon surface produces -vely charged surface sites due to the shift in the equilibrium of ionization of acidic functional groups and at this -vely charged site adsorption of metal ions take place. The optimum $\mathrm{pH}$ for the adsorption of $\mathrm{Pb}$ (II) on the activated carbon is found to be 5 .

\section{Adsorption isotherms}

\section{Langmuir isotherm}

Langmuir isotherm explains the formation of a monolayer heavy metal ions on the surface of the adsorbent and no further adsorption takes place after the formation of the layer. Langmuir isotherm is valid for monolayer adsorption onto a surface containing a finite number of identical sites. The model assumes uniform energies of adsorption onto the surface and no transmigration of adsorbate in the plane of the surface. The linear form of Langmuir isotherm equation is represented by

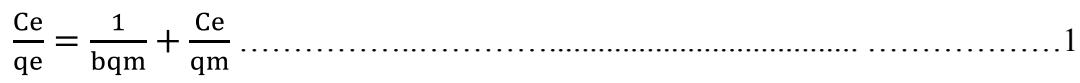

Where $\mathrm{Ce}$ is the equilibrium concentration of the adsorbate $(\mathrm{mg} / \mathrm{L})$ and qe is the amount of the adsorbate adsorbed under equilibrium while qm is the monolayer adsorption capacity $(\mathrm{mg} / \mathrm{g})$ and $\mathrm{b}$ is the Langmuir constant. Langmuir constant and adsorption capacity are determined from the slope and intercept of the plot Ce/qe versus Ce as shown in Fig 3.

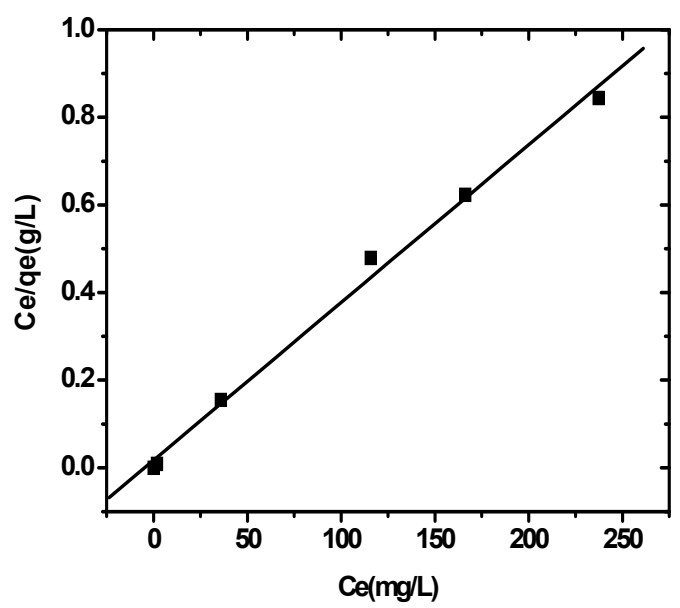

Figure 3: Langmuir isotherm of $\mathrm{Pb}$ (II)

\section{Freundlich isotherm}

This isotherm is used to describe the adsorption characteristics for the heterogeneous surface. Linear form of Freundlich isotherm may be written as:

$$
\log \mathrm{qe}=\log \mathrm{K}_{\mathrm{f}}+\frac{1}{\mathrm{n}} \log \mathrm{Ce}
$$




\section{J. Nepal Chem. Soc., Vol. 36, 2017}

Where $\mathrm{K}_{\mathrm{f}}$ and $\mathrm{n}$ are Freundlich constants related to adsorption capacity and adsorption intensity respectively.The values of Freundlich parameters can be calculated from the slope and intercept of straight portion of the linear plot obtained by plotting $\log$ qe versus $\log \mathrm{Ce}$, as shown in Fig 4 .

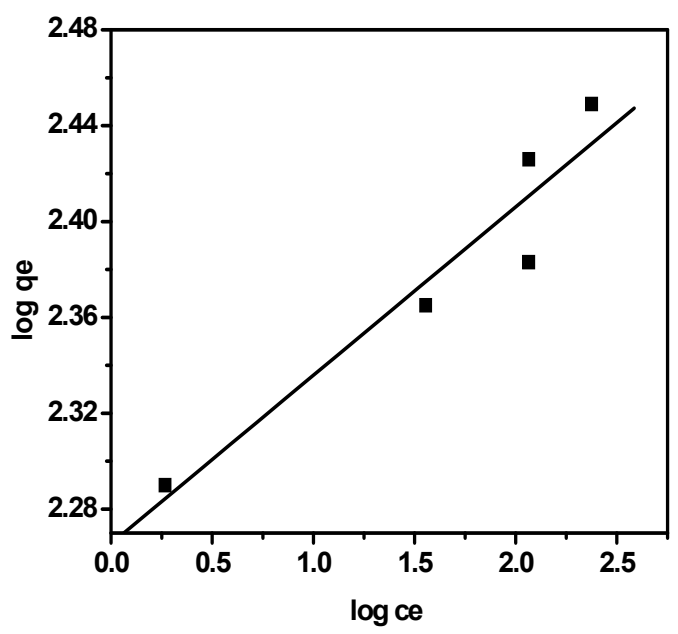

Figure 4: Freundlich isotherm of $\mathrm{Pb}$ (II)

Langmuir and Freundlich constants are given in Table-1. Fig-4 shows that the isotherm data better fits the Langmuir equation than Freundlich equation since the value of coefficient of determination $\left(\mathrm{R}^{2}=\right.$ 0.994) are higher than that of Freundlich isotherms $\left(\mathrm{R}^{2}=0.964\right)$. This supports the theory that the number of active sites on the carbon surface is limited and uptake of lead ions forms a monolayer on the surface. Langmuir and Freundllich parameters are shown in Table 1.

Table 1: Langmuir and Freundlich parameters for adsorption of $\mathrm{Pb}$ (II)

\begin{tabular}{|c|c|c|c|c|c|c|}
\hline \multirow{2}{*}{$\begin{array}{c}\text { Heavy } \\
\text { metal- } \\
\text { ions }\end{array}$} & \multicolumn{2}{|c|}{ Langmuir parameters } & \multirow{2}{*}{$\mathbf{R}^{2}$} & \multicolumn{2}{|c|}{ Freundlich parameters } & \multirow[b]{2}{*}{$\mathbf{R}^{2}$} \\
\hline & $\mathbf{q}_{\max } \mathrm{mg} / \mathrm{g}$ & b & & $K_{\mathrm{f}}(\mathrm{mg} / \mathrm{g})$ & (n) & \\
\hline $\mathrm{Pb}(\mathrm{II})$ & 277.8 & 0.209 & 0.994 & 184.3 & 14.28 & 0.964 \\
\hline
\end{tabular}

\section{Adsorption kinetics}

Adsorption kinetic study plays an important role to determine the efficiency of adsorption. In order to analyze the rate of adsorption pseudo-first-order and pseudo-second-order kinetic models have been applied to the adsorption kinetic data.

\section{Pseudo first order}

Pseudo first order equation was given by Legergren in 1898. According to Lagergren the pseudo first order equation is generally expressed as follows:

$$
\frac{\mathrm{dqt}}{\mathrm{dt}}=\mathrm{k}_{1}\left(\mathrm{q}_{\mathrm{e}}-\mathrm{q}_{\mathrm{t}}\right)
$$

$-118-$ 
Where $\mathrm{q}_{\mathrm{e}}$ and $\mathrm{q}_{\mathrm{t}}$ are the amount adsorbed at equilibrium and time $\mathrm{t}$, respectively $(\mathrm{mg} / \mathrm{g})$ and $\mathrm{k}_{\mathbf{1}}$ is the pseudo -first order rate constant $\left(\mathrm{Lmin}^{-1}\right)$.

After integration the equation (1) becomes as follows:

$$
\log \left(\mathrm{q}_{\mathrm{e}}-\mathrm{q}_{\mathrm{t}}\right)=\log \mathrm{q}_{\mathrm{e}}-\frac{\mathrm{k}_{1}}{2.303} \mathrm{t} \text {. }
$$

In order to test the validity of the kinetic model the value of $\log \left(q_{e}-q_{t}\right)$ against ' $t$ ' is plotted as shown in Fig. 5 .

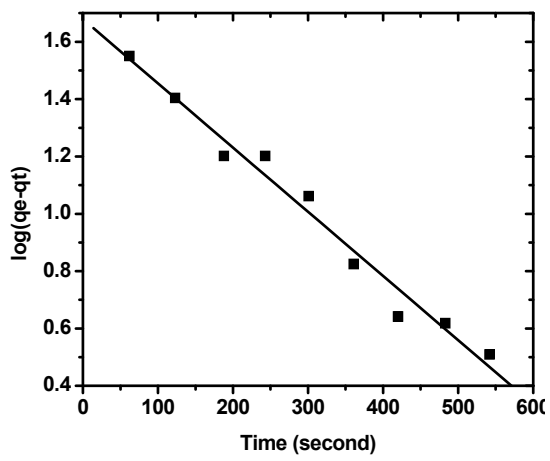

Figure 5: Pseudo first order plot for $\mathrm{Pb}(\mathrm{II})$

\section{Pseudo Second order}

The pseudo second order model is often called Ho second order model. The pseudo second order rate equation is represented as

$$
\frac{\mathrm{dqt}}{\mathrm{dt}}=\mathrm{k}_{2}\left(\mathrm{q}_{\mathrm{e}}-\mathrm{q}_{\mathrm{t}}\right)^{2}
$$

Where $\mathrm{k}_{2}$ is the second order rate constant of adsorption $\left(\mathrm{g} \mathrm{mg}^{-1} \mathrm{~min}^{-1}\right)$. Integrating the above equation with boundary conditions $\mathrm{t}=0$ to $\mathrm{t}=\mathrm{t}$ and $\mathrm{qt}=0$ to $\mathrm{qt}=\mathrm{qt}$ it becomes.

$$
\frac{1}{(\mathrm{qe}-\mathrm{qt})}=\frac{1}{\mathrm{qe}}+\mathrm{k}_{2} \mathrm{t} \text {. }
$$

The above equation can be rearranged to obtain

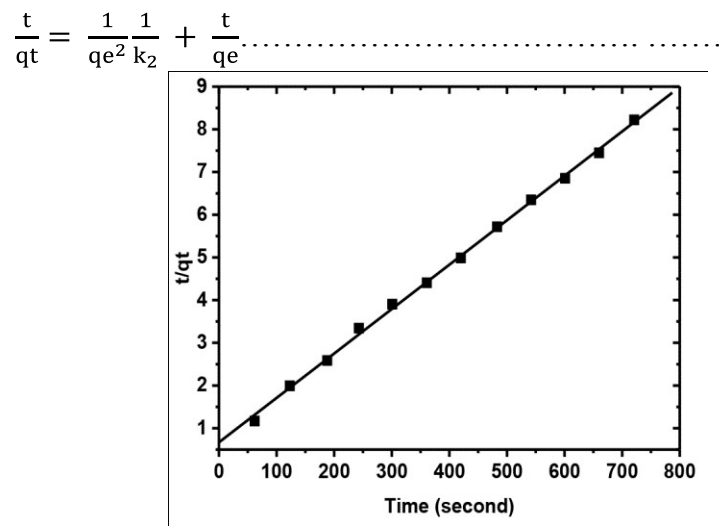

Figure 6: Pseudo second order plot for Pb (II)

$-119-$ 


\section{J. Nepal Chem. Soc., Vol. 36, 2017}

In order to study the adsorption kinetics by pseudo second order model adsorption kinetic data have been applied by plotting the value of $\mathrm{t} / \mathrm{qt}$ vs ' $\mathrm{t}$ '. The pseudo second order plots of $\mathrm{Pb}(\mathrm{II})$ is shown in Fig. 6 The values of $\mathrm{q}_{\mathrm{e}}$ and $\mathrm{k}_{2}$ are calculated from the slope and intercept of the plot and presented in Table 2 .

Table 2: Pseudo first and second order parameters for $\mathrm{Pb}$ (II)

\begin{tabular}{|c|c|c|c|c|c|c|c|}
\hline \multirow{2}{*}{$\begin{array}{c}\text { Heavy } \\
\text { metal } \\
\text { ions }\end{array}$} & \multicolumn{2}{|c|}{ Pseudo first order model } & \multicolumn{3}{c|}{ Pseudo second order model } \\
\cline { 2 - 8 } & $\mathbf{q}_{\mathbf{e}}(\mathbf{m g} / \mathbf{g})$ & $\mathbf{K}_{\mathbf{1}}(\mathbf{1} / \mathbf{m i n})$ & $\mathbf{R}^{\mathbf{2}}$ & $\begin{array}{c}\text { Experimental } \\
\text { value } \mathbf{q}_{\mathbf{e}}(\mathbf{m g} / \mathbf{g})\end{array}$ & $\mathbf{q}_{\mathbf{e}}(\mathbf{m g} / \mathbf{g})$ & $\begin{array}{c}\mathbf{K}_{\mathbf{2}}(\mathbf{g} / \mathbf{m g} \\
\mathbf{m i n})\end{array}$ & $\mathbf{R}^{2}$ \\
\hline $\mathrm{Pb}(\mathrm{II})$ & 47.71 & $5.158 \times 10^{-3}$ & 0.977 & 87.7 & 96.2 & 0.011 & 0.999 \\
\hline
\end{tabular}

\section{Conclusion}

Adsorption kinetic studies for $\mathrm{Pb}$ (II) adsorption has been investigated by using activated carbon prepared from Lapsi seed stone by chemical carbonization with concentrated sulphuric acid. Adsorption of $\mathrm{Pb}$ (II) is found to be $\mathrm{pH}$ dependent and optimal $\mathrm{pH}$ for adsorption is observed at $\mathrm{pH}$ 5.The optimum contact time for the adsorption of $\mathrm{Pb}(\mathrm{II})$ has been found to be180 minutes. It is found that equilibrium data was best described by Langmuir isotherm with higher value of coefficient of determination as compared to that of Freundlich isotherm showing a maximum uptake of $277.28 \mathrm{mg} / \mathrm{g}$. The pseudo has been found the best applicable adsorption kinetics to describe the adsorption process. The present work showed that the activated carbon prepared from Lapsi seed stone by chemical carbonization can be used as an effective adsorbent for the removal of $\mathrm{Pb}$ (II) from aqueous solution.

\section{References}

1. Chung-Hsin Wu1, Chao-Yin Kuo, Shu-Shian Guan, Adsorption Kinetics of Lead and Zinc Ionsby Coffee Residues, Polish Journal of Environmental Studies, 2015,Vol. 24, No. 2 , 761-767.

2. C.Karthika, N.Vinnilamani, S. Pattabhi, \& M Sekar, Utilization of Sago Waste as an Adsorbent for the Removal of $\mathrm{Pb}(\mathrm{II})$ from Aqueous Solution: Kinetics and Isotherm Studies, International Journal of Engineering Science and Technology, 2010,Vol. 2 (6), 1867-1879.

3. K. B. Payne, T. M Abdel-Fattah., Adsorption of Divalent Lead Ions by Zeolites and ActivatedCarbon: Effects of $\mathrm{pH}$, Tempe-rature, and Ionic Strength, J. Environ. Sci. Health, Part A, 2004, 39, 9, 2275-2291.

4. T.G.Chuah, A Jumasiah, Azni KI and SY Thomas SY., Rice husk as potentially low-cost biosorbent for heavy metals and dye removal an overview, Desalination 2005,175,305316.

5. I. Kula, M.Ugurlu , $\mathrm{H}$ Karaoglu and A Celik, Adsorption of Cd (II) ions from aqueous solutions using activated carbon prepared form olive stone by $\mathrm{ZnCl} 2$ activation. BioresourceTechnology, 2008,99: 492-501.

6. K.Srinivasan, N Balsubramaniam and T.V Ramkrishnan, Studies on chromium removalby rice husk. Ind.J. Eng. Chem.Res, 1998, 39, 376-387.

7. W.K,Anna, G.S.Roman and M Szymon., Biosorption of heavy metals from aqueous solutions onto peanut shell as a low cost biosorbent. Desalination, 2011,265: 126-134. 
8. F,Marquez, C.T Montesinos and J. Rodriguez, 2001, Powdered activated carbon from sawdust.Separation Science and Technology, 2001, 36, 3191-389.

9. M. Sekar, V. Sakthi and S. Rengarag, Kinetics and equilibrium adsorption study of lead (II) onto activated carbon prepared from coconut shell. Journal colloid and Interface Science, 2004,279, 307-317.

10. G.M Issabayeva K.NAroua and M.N.Sulaiman , Removal of lead from aqueous solution on palm shell activated carbon. Bioresource Technology, 2006, 97, 2350 -2355.

11. Mouni L, Merabet D, Bouzaza A and L. Belkhiri 2011, Adsorption of Pb (II) from aqueous solution using activated carbon developed from Apricot Stone, Desalination, 276, 148-153.

12. T. A. Bohli , N.F. Ouederni and I. Villaescusa,2012, Uptake of $\mathrm{Cd}^{+2}$ and $\mathrm{Ni}^{+2}$ Metal ions from Aqueous solutions by Activated Carbons from Waste Olive Stones. International Journal of Chemical Engineering and Applications, 2012,3(4), 232-236.

13. J.A.Muthanna, Preparation of Activated carbons from Date Stones by Chemical Activation Method using $\mathrm{FeCl}_{3}$ and $\mathrm{ZnCl}_{2}$ as Activating Agents. Journal of Engineering, 2011, ,17(4)1007-1022.

14. M.Y Miah, K.Volchek, K. W, Kuang. and F.H Tezel, Kinetic and Equilibrium Studies of Cesium Adsorption on Ceiling Tiles from Aqueous Solutions, Journal of Hazardous Materials, 2010,183, 712-717.

15. Ho, Y.S. and G McKay, Pseudo-Second Order Model for Sorption Processes. Process Biochemistry, 1999,34,735-742

16. P.O Boamah, Zhang, Q., Hua, M., Huang, Y., Liu, Y., Wang, W. and Liu, Y., Lead Removal onto Cross-linked Low Molecular Weight Chitosan Pyruvic Acid Derivatives. Carbohydrate Polymers, 2014,110, 518-527.

17. N.C Feng, X.Y Goo, Liang, S., Zhu, Y.S. and J.P Liu, Biosorption of Heavy Metals from Aqueous Solutions by Chemically Modified Orange Peel. Journal of Hazardous Materials, 2011,185, 49-54.

18. Barka Noureddine, Abdennouri Mohamed, El Makhfouk Mohammed, Qourzal Samir, , Biosorption characteristics of cadmium and lead onto eco-friendly dried cactus (Opuntia ficus indica) cladodes", Journal of Environmental Chemical Engineering, 2011,Vol.1 ,144-149 